\title{
Affordances theory as an operational framework for interpretation of past material culture and practices. Praxiography of things, bodies, and motions
}

\author{
Maciej Talaga \\ University of Warsaw \\ Faculty "Artes Liberales" \\ m.talaga@al.uw.edu.pl
}

Received 30 June 2018; accepted 27 December 2019; published 9 March 2020

\begin{abstract}
Material culture is seen as a sort of adaptation in humans' (and some animals') struggle with the natural environment. In this context, it is possible to say that culture integrates three aspects of embodied agency: the mind creates projects, the environment supplies materials, and the body provides the basic tool. This observation is important for reconstructing past manifestations of human embodiment, e.g. tools, anthropogenic landscapes, or somatic skills and practices. The present paper discusses the neo-materialist perspective on the objectives and methods of historical sciences which postulates extending the agenda of historical research by supplementing text- and discourse-centred studies with the 'mute', material relics of the past as yet another source of knowledge. This stems from the conviction that, as researchers engage physically with investigated objects and experience their affordances, they can gain crucial information which would be impossible or very problematic to convey in a written form. What this means for the reconstruction of material relics of the past or historical somatic skills is that the most complete source of knowledge is provided by a combination of historical context, especially the relics' culturally-defined function, and methodical practice (praxiography), which often enables overcoming difficulties posed by the inadequacy of available written accounts. The above observations were illustrated with three case studies presenting reconstructions of elements of historical material culture: the so-called 'Antikythera Mechanism', the 'Teutonic estoc' from the Princes Czartoryski Collection, and a medieval sword-fighting technique known as schiessen.
\end{abstract}

Keywords: affordance; praxiography; embodied research; neo-materialism; knowledge 


\section{Introduction}

Since the long-standing positivist and essentialist perspective in historiography had been challenged and largely overturned by the so-called 'textual turn' of the 1980s (Hicks \& Beaudry, 2010), constructivist or narrativist perspectives became paramount for the theory of historical inquiry. As put by Michael Schiffer, this led to the gradual detachment of material culture scholars from the very materiality which should presumably be at the core of their research. This resulted in a situation where:

The manufacture and use of artefacts is regarded (...) as just one more arena in which people negotiate culturally constituted meanings... (Schiffer, 1999, p. 6)

The approach saw material objects themselves as mere signs of extra-material cultural constructs and processes, such as identity, gender, aesthetisation, or landscape-building. In doing so, it proved insightful and very productive in terms of eliciting socially-produced cultural differences in material culture, but in exchange tended to ignore or even obscure inter-cultural similarities and their drivers (Olsen, 2003, p. 90-91). In consequence, another turn - this time a 'material' one - took place in the 1990s and sought to refocus material culture scholars on materiality per se (Clever \& Ruberg, 2014, p. 547).

Such renewed focus on material objects and their agency within cultural processes, often labelled as 'neo-materialism' (Lettow, 2017), by necessity called for a more 'experiential' or 'hands-on' approach to material sources which sparked a vivid philosophical and methodological debate that is still going on. Its critics pointed out the dangers posed by the lack of objectivity and the essentialist reductionism potentially involved in this approach. In his analysis of Frank Ankersmit's notion of "historical experience" as a way of direct knowing of the past, Kalle Pihlainen termed this aspect of the new materialism "historian's phenomenological yearning":

By and large, this phenomenological yearning - or the desire for experience - seems to play a role in history as a discipline too. And, in this aspect at least, history's dreams of objectivity and truth also reflect the elision of reality with experience. Because, that is, the past is unquestionably (once) real and existing on a common-sense level, this same common sense is allowed to cloud the distinction between historical and subjective pasts, and it encourages use of language and metaphors belonging to one in the other without sufficient critical reflection (Pihlainen, 2014, p. 110).

However, with a growing body of theoretical studies managing to convincingly undermine the long-standing Cartesian divide between mind and matter, recent critical reviews of the 'neomaterialist' trend in social sciences (Lettow, 2017) have largely rejected these objections:

Social theory has largely conceptualized the social, subjectivity and agency without taking into account the entanglements of human subjects and societies with the non-human world, living and non-living. The challenge that the new materialism poses is thus to take the critique of anthropocentrism and the turn to the materiality and the specific dynamics of the nonhuman world seriously without subscribing to ontological, scientistic and posthuman narratives (Lettow, 2017, p. 112). 
Similar conclusions have been formulated with regard to the above-mentioned experiential and hands-on approach to investigating material culture history, usually referred to as 'practice as research' (Arlander et al., 2017) or 'praxiography' (Clever \& Ruberg, 2014):

„With its methodology of ethnographic participant observation, praxiography focuses on bodies in practice, as an acting agent amongst other agents, such as sites, materials, and techniques. Thus, it allows space for the materiality of the body, but does not turn to essentialism: praxiography focuses on the ontological instability or multiplicity of the body, how it is differently enacted in every practice and has managed to form a seemingly natural unity" (Clever \& Ruberg, 2014, p. 562).

What is noteworthy in the above opinions is that they do not accuse new materialism of essentialism, despite this paradigm's inherent realism - new materialism's central postulate is that there exists an objective reality which has an impact on and is reflected by the cultural processes and thus can be to some extent inferred from them (Pihlainen, 2014, p. 112; Olsen, 2003, p. 88). This becomes understandable when one notes that the notion of 'reality' shared by most neo-materialist scholars does not refer to a time-stable, absolute state of matter(s). Instead, it is rather seen as a complex and ever-changing network of interrelations between various human and non-human actors, not all of which possess intentionality, but all of which do exhibit some sort of agency. Hence, main renderings of new materialism dismiss the realrelative or objective-subjective distinction (Hicks \& Beaudry, 2010, p. 5; Heft, 2001, p. 29). While reviewing Bruno Latour's Actor-Network Theory (ANT) as a framework for material culture studies, Björnar Olsen summarised it in the following way:

Reality is not to be found in essences, but in imbroglios and mixtures, the seamless and rhizome-like fabrics of culture and nature that link humans and non-humans in intimate relationships. It is a democratic and inclusive regime, everything can become actors (or actants) by being included into a network and assigned properties to act. It is a regime that cares for the hybrids and those hybrid relations that other systems (be they social or natural) largely have ignored (Olsen, 2003, p. 98).

This provides neo-materialists with a perfect vantage point for rehabilitating essentialism and trying to reconcile it with constructivism. Such an epistemological summersault is usually performed through emphasising the existence of a pre-conceptual, or "pre-phenomenological" (Segre, 2016, p. 308) flow of data supplied by the network of actors and actants of which a given perceiver is a part. This flow - called "pure experience" by William James (Heft, 2001, p. 26) - is at first received directly and subliminally, only then to be elaborated into conscious concepts. Such conceptualisation, as posited by neo-materialists, is not discretionary but has to respect some sort of pre-existing structure of the "pure experience", labelled variously by its different proponents. In his analysis of the philosophical roots of James J. Gibson's ecological psychology, Harry Heft repeatedly referred to it as a "latent structure", and hereafter this very term shall be used in the same way across the paper:

Selection of structure in experience involves following a set of relations in experience, and this is possible only because the relations between experiences are themselves experiencible. Relations in experience are transitional experiences which the world supplies. That is, the lines of structure selected out by the knowing function are not imposed on the thing 
known, but are identified or discovered in it (...). As already emphasized, pure experience has an intrinsic, latent structure (Heft, 2001, p. 30, emphases added).

What bears emphasising in Heft's definition is that it stresses that the latent structure is supplied by the world, discovered by perceivers rather than constructed by them, and relational. Even more importantly, it treats cognition and action as inseparable (enacted) and mediated by physical bodies (embodied). This means that the neo-materialist theories of knowing are in fact 'theories of practice' (Bueger, 2014, p. 383; for an apt example, see Ingold, 2009, pp. 9395). Similar views can be traced in the writings of many contemporary as well as older philosophers. Tim Ingold's “resistance of materials" (Ingold, 2011, p. 16), Kalevi Kull's “ecosemiotics” (Kull, 1998, p. 350), Edward F. Fischer's “cultural logic” (Fischer, 1999, p. 477), or Maurice Merleau-Ponty's “corporeal tissue" (Merleau-Ponty, 1996, p. 150) all seem to be very similar notions at the core. However, for the sake of brevity, this paper will not deal with their detailed comparison, especially given the still ambiguous applicability of these theories in research practice - like Bruno Latour's "flying saucers" (Latour, 1987, p. 242), they still show relatively little connection to the 'down-to-earth' work done by material culture scholars. Instead, the focus here is going to be on the ways in which the sentiment shared by these theoretical perspectives, that is the appreciation of the aboriginal structure of materiality or "flesh" (Olsen, 2003, p. 88), can be operationalised within an actual research strategy.

To this end, three attempts at reconstructing historical material culture will be discussed: two published studies and one unpublished, two of them by the author of the present paper. The choice had initially been made in order to examine how Heft's "latent structure" composed of affordances "which the world supplies" (Heft, 2001, p. 30) was used by material culture scholars, even if unbeknownst to them, to craft hypotheses about past materiality and practices and claim validity of their interpretations, and it was only later that its broader theoretical implications became apparent (more on this in the conclusion). It also ensures that this examination is not one-sided, since the selected studies approach the problem of reconstruction in three distinct ways - reverse engineering based on a partially preserved physical artefact (Freeth et al., 2006), exploration of a kinaesthetic potential of a physical artefact (Talaga, 2013), and a performative reconstruction of a physical bodily motion from a historical written account (Talaga, 2018). Of course, as "praxiography is on the one side very easy" (Bueger, 2014, p. 388), ${ }^{1}$ all the above-mentioned works, with a partial exception of the third, could be successfully conducted without relying on any particular theory of practice (knowing). Therefore, this paper is intended not as a critique of their results or methods, but as their reinterpretation from a select theoretical standpoint - the theory of affordances (Gibson 1979, p. 127) - in the hope of clarifying how these studies were grounded in their respective source bases. This, at

\footnotetext{
${ }^{1}$ Not to misrepresent Christian Bueger's view by putting his words out of context, it seems honest to quote the whole passage: „Praxiography is on the one side very easy, on the other quite intricate. It is straightforward since bodily movements and artefacts are often readily accessible and directly observable without the need for intricate interpretation procedures or major construction efforts. Studying movements and the use of artefacts is to start research with what is immediately accessible. The researcher needs to observe, watch, listen, and record. On the other side, the praxiographer is interested in what is by definition not readily available: the implicit background knowledge" (Bueger, 2014, p. 388).
} 
the same time, will serve to assess the applicability and, even more so, utility of the concept of affordances for investigating historical material culture and embodiment.

\section{Why the theory of affordances?}

James J. Gibson's ecological psychology is a theoretical approach to cognition that seems particularly fit for the questions at the heart of today's academic debates within the humanities and social sciences (one or both of which historiography is a part). With its equal treatment of human and non-human perceivers, focus on environmental agency, commensurability between the acting organism and its environment, rejection of the Cartesian dualism, and the relational (but not relative!) view on reality (Heft, 2001, pp. 109-116), it shows significant overlaps with other major frameworks, such as the ANT (Sanderson, 2003, p. 244). At the same time, it matches well with the questionnaire of problems related to the so-called Anthropocene (Latour, 2017). On the other hand, by being rooted in phenomenology and realism (Heft, 2001, pp. 114-123), it is at odds with representationist or constructivist perspectives which are not willing to accept the direct cognition that ecological psychology and similar theories advocate (Tonneau, 2013, p. 2). In the field of historical cultural studies, the point of greatest controversy is the relation between culture and nature - or in other words, the way in which humans construe their environment. There, direct cognition is deemed unacceptable by many historians and anthropologists, as it allegedly fails to account for the socially-constructed aspects of the environment. ${ }^{2}$ However, as summarised by Heft, these objections, albeit largely unaddressed by Gibson himself, are not left without an answer by modern ecological psychologists who accentuate the reciprocity in the nature-culture relation:

Costall (1999) argued that the ecological approach seems to treat environments »as existing prior to, and independently of, organisms, and adaptation ... as a 'fitting in' of organisms to those pre-existing conditions « (p. 413). However, because the human environment is a product of sociocultural activities, it cannot be said to be independent in the sense of existing prior to human activities (...). This is a valid point. But it does not undermine the ecological claim that (...) the sociocultural world, including social processes, institutions, and so on, is a product of individuals' ongoing collective transactions with the environment over historical time. Because of the dynamic and changing nature of the environment as a result of human actions (setting aside other sources of environmental change for the moment), the reciprocity, or »mutualism, « of individual and environment must be given its due. But at any specific moment for an individual, the environment is »already there« as a context for that person's actions (Heft, 2001, p. 124).

In other words, the fact that the environment is partially shaped by anthropogenic factors does not make it any less 'direct' or 'natural', in the sense that any transformation of it has to begin from a certain state which was formed beyond complete control of a given individual (or generation). It is even clearer if relations established by and between other living or non-living actors and their impact on (re)shaping the environment are included in the equation (e.g. Dwiartama \& Rosin, 2014). Whether it is called "agency" or "consequences" (Hornborg,

\footnotetext{
${ }^{2}$ In its more radical renderings, this school of thought posits that the environment does not exist but as a social construct (e.g. Bender, 2002).
} 
2017), non-living material objects of anthropogenic or environmental origin have a deep and often inapparent impact on the dynamics of relations within processes, networks, or systems. What is perhaps most important from the perspective of material culture and praxiography studies, however, is that under certain conditions material objects possess the capability to 'outlive' their original creators (or users) and thus effectively extend their agency in time and space. ${ }^{3}$ Heft terms this feature of materiality "ecological knowledge" and uses it to once again to underscore how the cultural and the natural are inherently intertwined within the environment:

Some basic features of the terrestrial environment (e.g., ground surfaces, graspable and liftable objects, and water) have functional meanings for a perceiver apart from social processes (although this is not to say that these affordances are necessarily learned apart from social processes). By far the most abundant meaningful features of the environment are those shaped out of the materials of the environment and through coordinated social actions. In many of these cases, some of the things we have come to understand about the effects of certain actions on the environment we have subsequently built into environmental structures themselves. These latter constructed embodiments of what is known-which include tools, artifacts, representations, patterns of action, and institutions - can be called ecological knowledge (Heft, 2001, p. 330, emphases added).

For the central problem of this paper, that is the operationalisation of historical material culture reconstruction, the quoted passage is of utmost importance. First of all, the notion of "ecological knowledge" corresponds with the postulates advanced by the proponents of 'practice as research' to use the very materiality of artefacts or environment as a source of knowledge about the past on a par with textual evidence, while keeping in mind that these non-textual sources cannot be 'read', but have to be 'engaged' (Olsen, 2003, p. 96). In order to make such engagement fruitful in terms of knowledge (re)construction, researchers have to make it a process, not just an isolated episode, if they want to allow for the potential depth of the sources to unfold:

Repetitive engagement with the material world has the potential to open up new research avenues for historians, through a greater awareness of the questions prompted by things. It also provides a means of developing much-needed material literacies and extending and expanding modes of attention (Smith \& Hannan, 2017, p. 44).

These "material literacies" correspond well with Heft's "ecological knowledge", as well as with observations of scholars dealing with "embodied relations" between tools and agents, who tend to emphasise that " $[t]$ he fundamental relational unit of the »agent + tool « confronts the world in a markedly different way than the non-relational unit of »the agent without the

\footnotetext{
${ }^{3}$ A common example would be human-made objects, such as plastic litter, buildings with asbestos, or devastated post-industrial spaces, which over time became rejected, yet remained an inconvenient or even threatening part of the physical, material reality. More sophisticated but perhaps stronger cases would be Alfred Gell's concept of "distributed personhood" (Gell, 1998, pp. 20-21) or the lasting cultural repercussions of the Chernobyl disaster which created 'the zone' "where radioactive radiation has become the determinant of the boundaries and time intervals” changing ,the experience and existence of the affected space” (Brylska, 2018, p. 111).
} 
tool «" (Chakrabarty, 2018, p. 253) and that the perceived knowledge content of user-tool interactions tends to "expand and open up in proportion to the amount of attention it is paid" (Spatz, 2015, p. 63). Hence, a crucial step on the way to translating these general observations into concrete, meaningful research data, that is to operationalise them, is to establish how exactly "repetitive engagement" entails "material literacies". A useful conceptual framework in this regard was introduced by Ben Spatz who proposed to call any specific instance of somatic (embodied) activity by the name of "practice" - that is a moment of action, unique and unrepeatable due to the unstable nature of agents and their environments (Spatz, 2015, p. 41). On the other hand, he noted that despite the fact that practice is impossible to repeat in absolute terms, one can still intuitively 'feel' that 'the same' action can be performed again and again. ${ }^{4}$ This feeling is justifiable, according to Spatz, because different "practices", although they show certain variation, can indeed share enough similarities to be considered tightly-related and he proposed that what allows an agent to repeat very similar practices in different contexts is "technique":

[Similarities between practices] can be seen as an area of technique, or as the knowledge content of specific practices. In other words, the relationship between technique and practice is epistemic. This finally allows us to understand what may connect my practice of swimming or dancing with that of people living thousands of miles away or hundreds of years ago. If we are doing the »same thing, « that is precisely and only because we are making use of the same technique, the same knowledge of what is reliably possible given the similarities we find in our bodies and environments (Spatz, 2015, p. 41; emphases after the original).

From this perspective, researchers' "repetitive engagement" (Smith \& Hannan, 2017, p. 44) with materiality is a series of instances of "practice" (Spatz, 2015, p. 41) capable of revealing the "technique" pertaining to them. Therefore, the definition of reconstruction in the case of investigating historical somatic skills or material artefacts cannot be to 'repeat past practice', that is to re-enact how a given person moved at a particular point in time, which would be impossible (Burkart, 2016b, p. 17), but rather to 'understand past technique'. Understanding technique in this case should be seen as the ability to paraphrase the engaged knowledge, either in the form of new, but compatible, practice (Wilson \& Peterson, 2006, p. 4-5) or its translation into some sort of language potentially enabling practice production (Brożek, 2018, p. 181). The latter option would require developing a clear method for itemising the "knowledge content" to be translated, and this is where the affordances theory may prove valuable.

Since the affordances, introduced by James J. Gibson, founder of the ecological psychology, are defined as "what [the environment] offers the animal, what it provides or furnishes, either for good or ill" (Gibson, 1979, p. 127), they seem well-suited for the task of eliciting the functional properties of materiality revealed through historians" "material literacy" developed during their "engagement" with the investigated matter. Especially that they are neither objective nor subjective, and relatively time-stable for a given species (Heft, 2001, pp. 132-135, 332), which is their major advantage for historians interested in establishing any sort of 'historical

\footnotetext{
${ }^{4}$ Ben Spatz illustrates this through an example of cooking 'the same' meal on different occasions - what forms the basis for the supposed 'identity' of different instances of cooking ('practice') is the underlying recipe ('technique’) (Spatz, 2015, p. 39).
} 
truth'. The following short case studies, as announced earlier, will serve to illustrate such an application of the affordances theory. Finally, this application will reveal several unobvious aspects of the nature of affordances themselves.

\section{The Antikythera Mechanism: a case study of conceptual reconstruction and cultural affordances}

The Antikythera Mechanism is an ancient mechanical device presumably designed to help calculate the movements and positions of celestial bodies. Discovered in a shipwreck near the Greek island of Antikythera, currently held by the National Archaeological Museum in Athens, and dated to the $2^{\text {nd }}$ century BC, it is believed to be the most technologically-advanced mechanism until the $18^{\text {th }}$ century AD (Freeth et al., 2006).

The mechanism is very sophisticated - built from several circular plates made of metal joined with axes allowing rotation, it is additionally covered with numerous and sometimes cryptic inscriptions in ancient Greek. Its reconstruction was even more complicated due to different state of preservation of its particular parts, ambiguous reading of the inscriptions, as well as unclear functional relations between the plates and the axes. However, at the same time, the attempt at its conceptual reconstruction, supplemented with digital imaging, by Tony Freeth and his collaborators from the Antikythera Mechanism Research Project is a simple example of using affordances as a touchstone for the truth value of reconstructing an historical artefact of material culture. ${ }^{5}$ What is also noteworthy is that the affordances that were at play during their study were of twofold origin: the objective spatial relations (that is what westerners call 'geometry') were provided by the latent structure of the world, whereas conceptualisations of celestial bodies potentially known to the maker(s) of the Mechanism were provided by their cultural environment. Hence, the researchers dealt with what may be called 'physical affordances', which are not human-made, and 'cultural affordances', which are a product of humans' shared imagined realities.

\subsection{The geometry}

The main part of the Mechanism consists of a system of gears, which means that in order to achieve their intended functionalities, its maker(s) had to follow certain rules imposed by the physical reality that limited the ways in which the gears could be joined to one another - that is, they had to face Ingold's "resistance of materials" and respect Heft's "latent structure" of the materiality of the world. This means that when analysing each hypothetical reconstruction of how the gears were positioned and connected, the researchers had to analyse what affordances were provided by the physical, material structure of these artefacts. A detailed description of this process, supplemented with computer images and mathematical calculations for different hypothetical arrangements of the gears, can be found in the original paper (Freeth

\footnotetext{
${ }^{5}$ To be clear, Freeth and his team do not reference ecological psychology at all in their publications. It does not, however, mean that their outcomes and methods cannot be presented from the ecological perspective, as noted earlier.
} 
et al., 2006: Supplementary Note 3). Its simpler and less formal rendering can be also found in a conference speech given by Freeth (2013).

\subsection{The ancient calendars and on combining the physical and the cultural affordances}

Given that several competing conceptualisations of the astronomical cycles were known in Antiquity - for instance, the older Metonic or the younger Callipic cycle - the researchers, having established the astronomical character of the mechanism, could interpret the geometrical arrangement of the gears and axes of the Mechanism observable in its state of preservation in more than one way. Depending on the assumed astronomical theory behind the structure, certain axes could be interpreted as fixed or rotatory, while the existence of some gears currently missing could be postulated or excluded. These cultural factors influenced the choices of the Mechanism's constructors in a similar way to the geometrical constraints, directing their efforts towards specific ends resultant from their socially-constructed image of the celestial order. Hence, only through a meticulous analysis of the physical structure of the artefact combined with a thorough knowledge of the conceptual frameworks potentially impacting its functionalities was it possible to disprove false hypotheses regarding its reconstruction proposed in earlier studies (for details, see Freeth, 2012). For the sake of brevity, let one citation serve as an example. It is particularly interesting, as it refers to a certain part of the artefact, marked 'e3', whose function remained entirely unknown before the study by Freeth and others, and aptly illustrates the combined effect of investigating the physical and cultural affordances:

Of particular note is the dual use of the large gear, e3, at the back of the mechanism, which has found no use in previous models. In our model, it is powered by $\mathrm{m} 3$ as part of a fixedaxis train that turns the Saros and Exeligmos dials for eclipse prediction, and also doubles as the 'epicyclic table' for the gears k1, k2. These are part of epicyclic gearing that calculates the theory of the irregular motion of the moon, developed by Hipparchos sometime between 146 and 128 BC (ref. 22) - the 'first anomaly', caused by its elliptical orbit about the Earth. The period of this anomaly is the period from apogee to apogee (the anomalistic month). To realize this theory, the mean sidereal lunar motion is first calculated by gears on axes c, $\mathrm{d}$ and e and this is then fed into the epicyclic system. As explained in Fig. 6, a pin-and-slot device on the epicyclic gears $\mathrm{k} 1$ and $\mathrm{k} 2$, clearly seen in the CT, provides the variation. This was previously identified, but rejected as a lunar mechanism. The remarkable purpose of mounting the pin-and-slot mechanism on the gear e 3 is to change the period of variation from sidereal month (that is, the time taken for the Moon to orbit the Earth relative to the zodiac), which would occur if $\mathrm{k} 1$ and $\mathrm{k} 2$ were on fixed axes, to anomalistic month - by carrying the gears epicyclically at a rate that is the difference between the rates of the sidereal and anomalistic months, that is, at the rate of rotation of about 9 years of the Moon's apogee (Freeth et al., 2006, p. 590).

In summary, whereas the function of the Mechanism was influenced by culturally-constructed imagined reality (ancient calendars), its structure referred to something not culturally-dependent (actual motions of the celestial bodies observable from the Earth). The latter matches the definition of Heft's "latent structure" mentioned earlier and is an example of a time-stable environmental feature containing the afore-mentioned "ecological knowledge" which makes 
it possible for modern researchers to get close to the experience of people living in the past and reconstruct their knowledge ('technique' according to Spatz) reflected in specific artefacts of material culture ('practice').

\section{The 'Teutonic estoc': a case study of cultural suppression of affordance perception}

The 'Teutonic estoc' from Kraków, Poland, is a sword of unusual construction dated broadly to the $14^{\text {th }} / 15^{\text {th }}$ century AD. In the $18^{\text {th }}$ century, it was moved from the Royal Treasury of the Kingdom of Poland to an art collection assembled by the Duchess Izabela Czartoryska. Currently it is held and exhibited as a deposit by the Armoury of the Wawel Royal Castle in Kraków, Poland (Talaga, 2013).

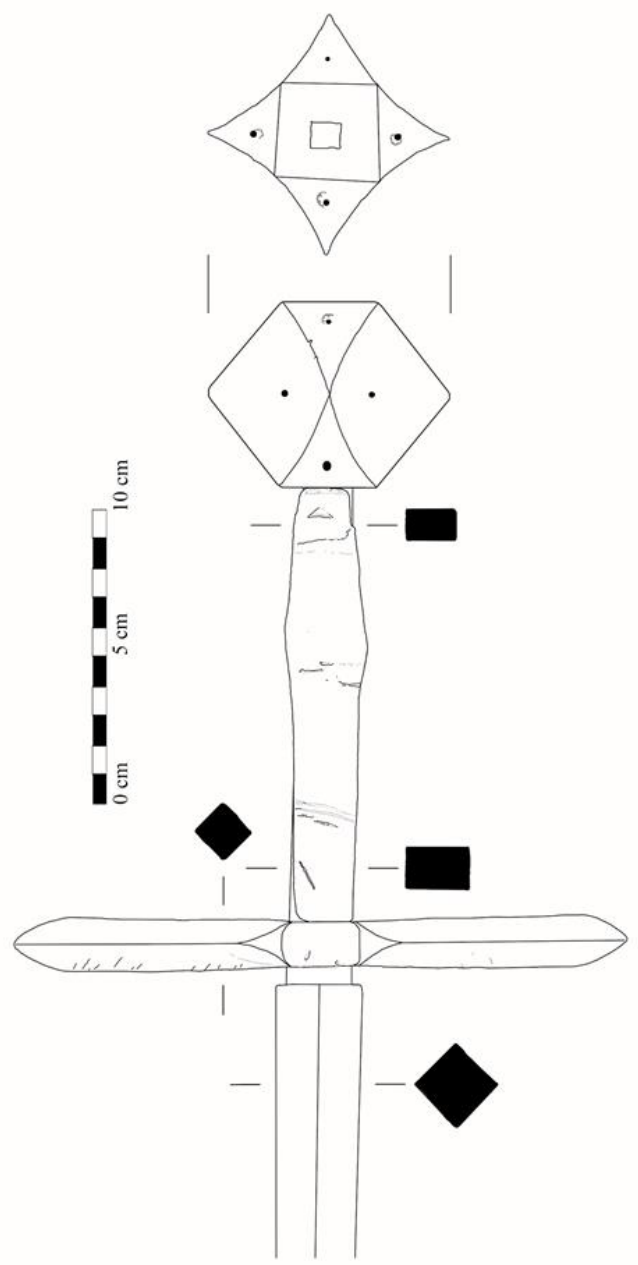

Figure 1. The 'Teutonic estoc' from the Princes Czartoryski Collection. Currently a deposit on exhibition at the Wawel Royal Castle Armoury, Kraków, Poland. Drawing by M. Talaga. 
This artefact has been subjected to various interpretations over the last several decades and raised much controversy, especially in the 1950s through 1970s (Talaga, 2013, pp. 9-11). What proved particularly problematic was its atypical construction, size, and weight which made it very difficult for arms and armour scholars to classify it with the use of existing typologies (Talaga, 2013, p. 18-21). To borrow the terms from the affordances theory, the scholars realised that this weapon did not 'afford' what is typical of swords - it was unsuited for cutting or sharpening, and could not be efficiently wielded neither with one hand alone (due to weight and balance) nor two hands (due to a very short grip and unwieldy pommel). At the same time, its construction suggests some other affordances - the pommel resembles a head of a mace, the quillons come in the form of robust, protruding spikes, while the blade is thick, square in cross-section, and thus extremely stiff (Fig. 1). However, the scholars had no idea what to do with these observations.

The answer became obvious, though, when more recent research included a category of written sources previously not consulted in this context - the late-medieval martial arts manuals ('fight books'; see Jaquet, Verelst, \& Dawson,, 2016) which discussed the methods of armoured combat. Not only did they contain descriptions and iconography of analogous weapons, this way attesting to the authenticity of the 'Teutonic estoc', but they also provided a detailed list of combat techniques designed specifically to fully capitalise on these weapons' unusual construction (Fig. 2). In other words, the expanded source base revealed affordances which shed a new light on what was previously seen as an odd and non-functional material artefact. Therefore, the 'Teutonic estoc' should now be seen as a specialised tool, intentionally designed so as to use certain affordances offered by the materiality of the weapon itself as well as by human embodiment (that is how the construction of the sword affects its efficiency against a fully armoured body of the opponent). At the same time, it also provides certain affordances to the user (that is a possibility to defeat a well-protected opponent), thus expanding their agency, but only under the condition that the user has sufficient embodied knowledge ('technique').

In this context, the 'Teutonic estoc' acts like a repository of "ecological knowledge" - its form 'codes' deep understanding of applied physics, technological process, and combat skills which have escaped modern arms and armour experts for a long time. These affordances remained hidden and it is hard to imagine that modern scholars would have ever been able to discover them without the access to the medieval fight books. For the best part, affordances are discovered not through abstract reasoning, but rather physical engagement with the materiality of the world (Spatz, 2015, pp. 42-43; Heft, 2001, p. 131) - and no sane modern historian would ever attempt to bludgeon their armoured colleague down with a sword in order to explore the latter's affordances.

On the one hand, this observation is well in line with the pragmatist assumption underlying the ecological psychology that the truth value of cultural concepts lies in their functionality within their intended contexts (Heft, 2001, pp. 40-45, 131). On the other, however, it reveals the difficulty inherent to any attempts to use such a pragmatic, functional criterion in search for the 'historical truth'. When a historian or archaeologist strives to reconstruct or re-enact some past skill, they have to remember that what works in one cultural milieu may prove inefficient when moved to a different one (Spatz, 2015, pp. 42-43, 65-67). To stay with the armoured combat as an example: nowadays there exists a dynamically-developing sport in 
which competitors fight each other with replicas of medieval arms and armours, while the rulesets allow for delivering full-contact blows to the opponent or even throwing them to the ground (Radtchenko, 2006). One could expect that in such a liberal environment, the armoured combat techniques preserved in medieval fight books (Fig. 2) would become (re)discovered quite soon. However, the rules of this modern sport state that points are awarded for striking any part of the opponent's body, even if it is fully protected by the armour rendering the blows harmful, thrusting with the point of the sword between the plates of the armour is strictly prohibited, and the gloves protecting fighters' hands are modified for safety reasons so that they make it impossible or uncomfortable to hold the sword in any way, except by the grip. As a result, a typical modern competitor is entirely unaware of and disinterested in the swordfighting methods described in the medieval fight books.

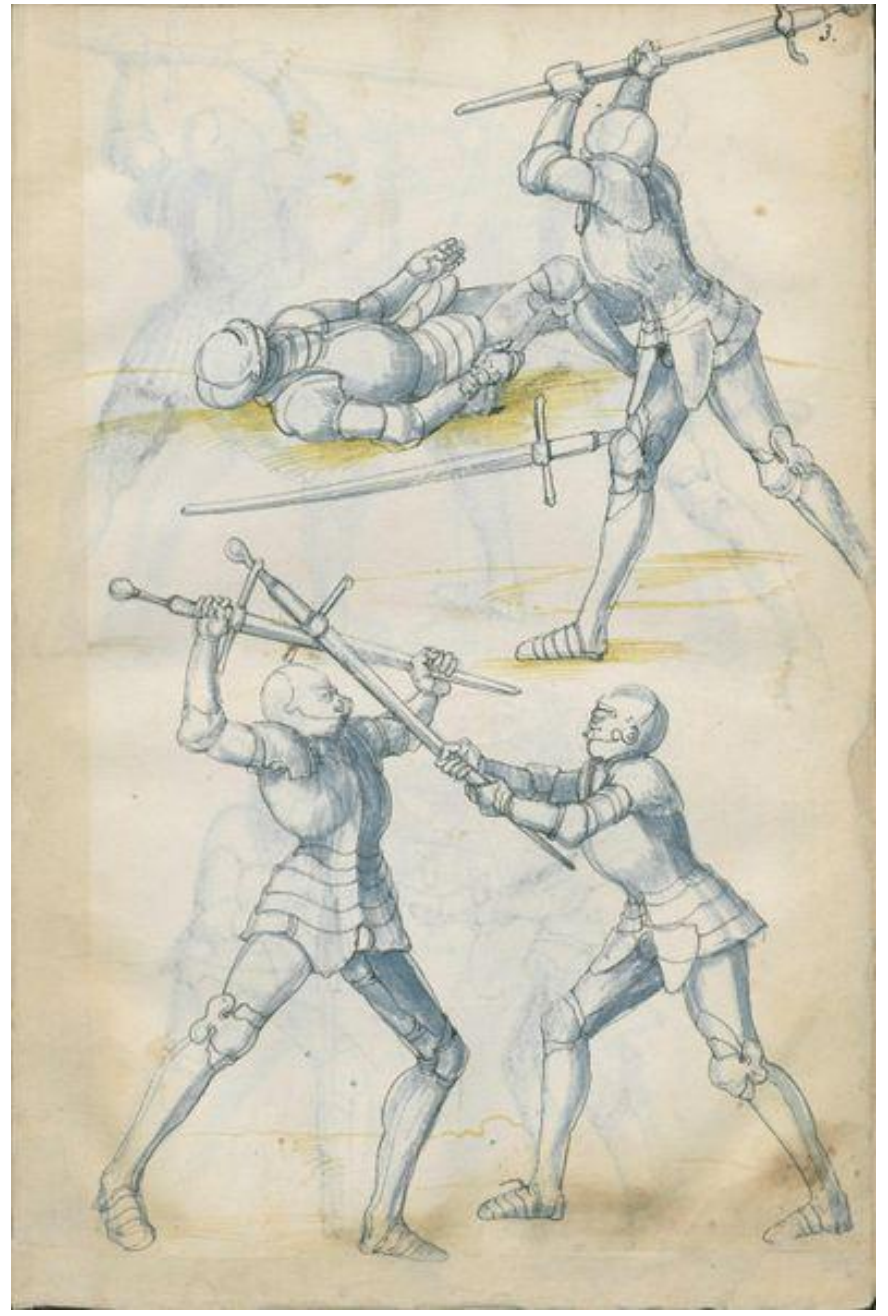

Figure 2. Examples of sword-fighting techniques optimised for armoured combat. Source: A. Dürer (1512). Berlin Sketchbook (Lib.pict.A.83), folio 3r. Staatsbibliothek zu Berlin, Berlin, Germany. 
Hence, it can be summarised that people socialised within the modern western cultural context are not ready (and luckily so!) to create such an environment which would enable an unrestricted experimentation with all kinds of historical skills. Therefore, it would be a mistake to assume that something functioning well today would behave in the same way in the past, or the other way round. Such a diachronic perspective underscores the dynamic and relational nature of affordances, as well as highlights the limits of praxiography as a mode of historical inquiry.

\section{Schiessen or 'shooting' the sword: a case study of affordance-driven reconstruction of an historical somatic skill}

The third case to be discussed here shall illustrate how a rigorous analysis of the cultural and physical milieu of an artefact known from historical records enables pin-pointing the affordances behind its functionality, and thus discovering why some of its modern reconstructions prove to be unsatisfactory in practice.

Unusually, however, the discussed artefact will not be a physical object, but a motion or, to be more precise, what Marcel Mauss proposed to call a "technique of the body" (Mauss, 1973). This technique is schiessen (German: 'shooting'), a combat move described in a German latemedieval fight book known as the 'Nuremberg Codex'. ${ }^{6}$ Attempts at reconstructing the somatic content of this book, that is the combative skills described therein, have been conducted since the late 1990s, but only recently have they attracted the attention of the academics (Burkart, 2016a, pp. 453-454). This research combines codicological and linguistic analysis of the source itself with "embodied research" (Spatz, 2015, p. 2), that is regular, prolonged, and practical experimentation with the motions encoded in it.

There is no room for a detailed description of the source in this paper, especially that the relevant information can be found elsewhere (Burkart, 2016a). There is also no need for a detailed discussion of all the facets of the schiessen as a combat move - the linguistic aspects of its reconstruction have already been discussed in a publication (Talaga, 2019), whereas a complete description of the process of reconstruction with accompanying video documentation is already available in English at an online vlog, 'Sprechfenster Blog' (Talaga, 2018). Therefore, here the attention will be focused on what proved to be a pivotal difficulty related to the reconstruction of schiessen, as well as on the way in which the notion of affordances was applied to its conceptualisation and contributed to the final solution.

As already stated earlier, functionality is the key criterion for assessing the truth value of a somatic technique, but at the same time it is a criterion laden with cultural content and thus potentially misleading for historical research. In the case of schiessen, individual combat with a long, two-handed sword was the context, whereas its particular function within this context was to ensure maximal reach of the weapon and stop the opponent from approaching and delivering their own attack. Importantly, schiessen is a kinaesthetic component of several combat moves (German: Stücke or Gefechten), some of which are rather unproblematic to interpret

\footnotetext{
${ }^{6}$ Currently held by the Germanisches Nationalmuseum in Nuremberg, Germany, under the inventory number HS 3227a. Digitised version available at: http://dlib.gnm.de/item/Hs3227a/html
} 
and reconstruct (Talaga, 2018). However, one example of the application of schiessen described in the 'Nuremberg Codex' has long resisted any functional reconstruction and undermined researchers' confidence in the validity of their interpretations of the other instances of this combat technique.

The problematic example comes from the passage dealing with a combat move called Schielhaw (German: 'squint-hew'), which states that: "whoever threatens with changing-through [Durchwechseln], they become shamed with the squint-hew. And one shall deliver the squinthew fully and long enough and shoot [schiessen] the point firmly. Otherwise, he will become impeded with changing-through and one shall squint fully with the point into the throat bravely without fear" (HS 3227a, folio 28v).

To clarify, Durchwechseln is a motion in which the point of the sword is moved to the other side of the opponent's weapon in order to deliver a thrust at an unprotected target. This means that in Durchwechseln the swords are not crossed at the onset of the attack and neither of the adversaries is protected by their weapon. Consequently, researchers-practitioners trying to perform schiessen according to the description from the passage on Schielhaw most often find themselves in the so-called 'double hit' - a situation when they get hit by their opponent in return at the very moment they hit with their own attack (Fig. 3). Obviously, it is not a desired outcome for neither of them.

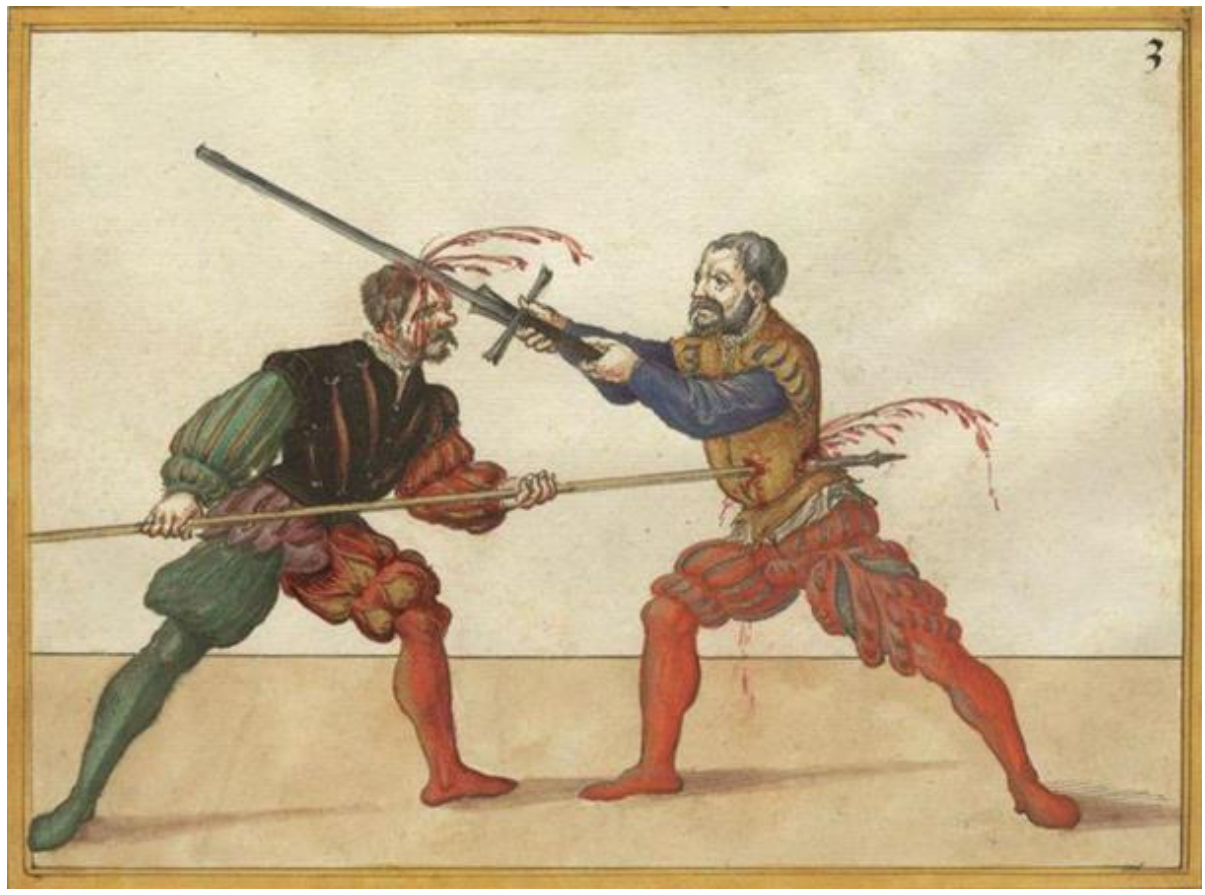

Figure 3. A depiction of a 'double hit'. P. H. Mair (ca. 1540). Opus Amplissimum de Arte Athletica (MSS Dresd.C.93), folio 228r. Sächsische Landesbibliothek, Dresden, Germany. 
Clearly then, the technique preserved in this historical source failed to produce viable practice in a modern context. This has convinced some researchers that either the way schiessen against Durchwechseln was described in the 'Nuremberg Codex' is flawed, perhaps due to some scribal mistakes, or that the whole fight book was written by a fraud, who had never tested all the combat moves he described in practice.

However, if one assumes that the description is accurate and based on real-life knowledge, then it becomes necessary to ask whether the context of modern practice of the said reconstructed historical technique enables its functionality. In other words: do researchers correctly identify the affordances on which this technique was based? A prolonged experimentation (praxiography) suggested several key factors at play in this regard (Talaga, 2018).

\subsection{Maximisation of the effective range of attack offered by a medieval two-handed sword and human anatomy}

Similarly to the Mechanism form Antikythera, two sword-fighting adversaries and their weapons are a dynamic system in which geometry plays an important role. When assessing the maximal range of attack possible in such circumstances, the first step is to investigate the spatial arrangement of a joint functional unit consisting of a human and his tool (sword) and the affordances the latter provides in this regard. As long as this question remained unaddressed, all attempts at performing schiessen failed to produce results that would be compatible with the technique (that is, schiessen's description in the source). An optimal motor pattern, that is one that realised all its functions defined by the source, was based on the following affordance: the sword is guided with the arms which are attached to the torso at the height of the shoulders (in humans); from there, the geometrically shortest path to schiessen's intended target - the throat - runs at shoulder height, with the sword placed in parallel with the ground. Any other line will by necessity be longer, and so - the reach would be compromised (Fig. 4).

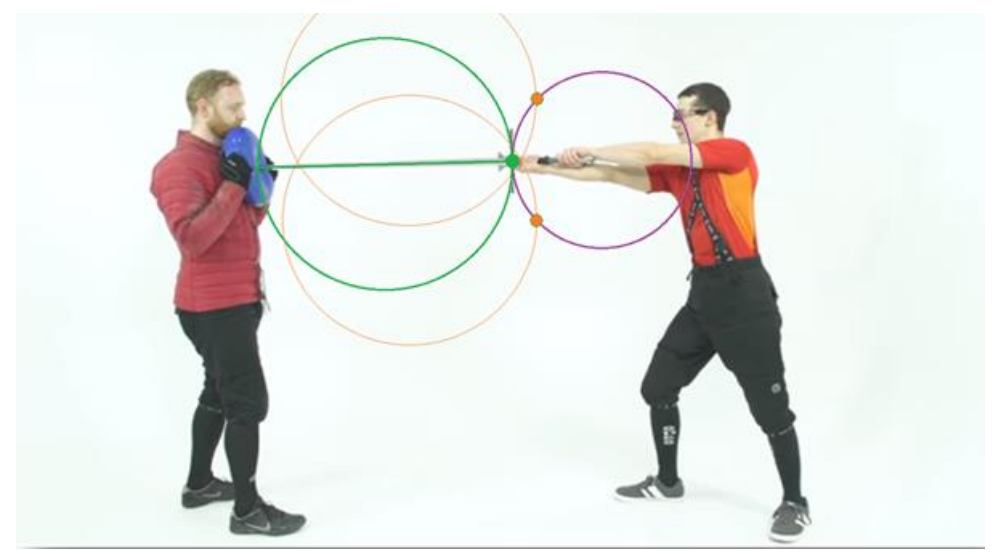

Figure 4. A still from the video documentation of praxiographic exploration of the affordances of schiessen. The circles illustrate the difference in reach between the optimal positioning of the hands and the sword (green) and the suboptimal (orange and purple). Source: Talaga, 2019; compiled by M. Talaga. 


\subsection{Dynamics of the physical impact of the attack on the bodies of both opponents}

When the hit occurs, all the bodies collide together and the energy of this collision is dispersed between the person hit, the weapon, and the person hitting. Each of the 'participants' of this collision contributes in some way to the physical dynamics of the whole. Without delving into unnecessary details, one of the key features of this whole is stiffness or pliability. If both attacking bodies involved - the attacker and his sword - were perfectly stiff and grounded, then the whole energy would have to be absorbed by the body receiving the hit. However, if the sword or the attacker's body showed certain pliability, then they would bend upon impact and thus decrease the damage dealt to the attacked party. The earlier suboptimal performances of schiessen failed to include the following affordances:

1. any sword is flexible along its long axis in the plane parallel to its flat sides; however, this feature is much more pronounced in modern training swords which are deliberately made so as to ensure significant flexibility due to safety reasons;

2. the power of a sword attack is generated only partially by the arm muscles, with the majority of power coming from the legs and torso. This suggests that if the tension of postural muscles is weakened, schiessen also becomes significantly weaker and more pliable;

3. the power generated by the legs and torso is transferred into the sword optimally by pushing until the arms are fully extended towards the target, which synergises with the affordances described a propos the maximisation of range.

In consequence, thrusts delivered not at shoulder height and with the sword not in parallel with the ground carried less force. If this flaw was combined with a suboptimal engagement of the postural muscles and a flexible training sword, the whole thrust was too structurally weak to stop the opponent in the middle of their offensive approach. And conversely, including the above affordances during experimentation produced schiessen that was structurally strong enough to stop the approaching opponent mid-way.

\subsection{Neuro-physiological reaction to being hit}

In addition, the praxiographic exploration and the broader context provided by historical accounts suggested the existence of yet another affordance which was not mentioned explicitly in the 'Nuremberg Codex' and cannot be directly tested in practice. It is the so-called 'withdrawal reflex' (Martin, 2008, p. 519). In short, it consists of an involuntary and immediate retraction of a body part exposed to an acute aversive stimulus, such as high temperature or penetration by a sharp object. This phenomenon is understood here as an affordance from the perspective of the fencer attacking with schiessen, since it enables them to expect that if they manage to hit the throat early, before the opponent had committed fully to his own attack, they would stop a counter-offensive and thus remain safe and avoid a 'double hit'.

On the one hand, all the above-mentioned affordances, analysed jointly, explain why schiessen could be safely directed "with the point into the throat bravely without fear" of being hit in return, as advocated in the 'Nuremberg Codex' (HS 3227a, folio 28v). On the other hand, they 
simultaneously demonstrate why the same combat move performed in modern contexts usually results in a 'double hit' - flexible training swords and other safety gear (e.g. fencing masks) largely neutralise the pushing effect of schiessen, not to mention that they make it impossible to actually penetrate opponents' bodies with the point of the sword. This, in turn, significantly weakens or entirely eliminates the withdrawal reflex as an affordance present during a violent sword-fighting encounter. Accordingly, the modern contexts in which medieval fencing is usually practiced and experimented will tend to lack the key affordances on which the technique of schiessen was founded.

\section{Closing remarks}

In conclusion, the above case studies were originally intended as examples demonstrating how Gibson's affordances theory brings added-value to the so-called 'praxiography' in historiography, that is historical research aimed at investigating how past practices were embedded in material aspects of the past reality - be it things or bodily motions. In doing so, they demonstrated that this added-value was of a twofold nature. Firstly, by considering the environment as an inseparable mixture of nature and culture and using the notion of affordances as a tool for discovering and operationalising the functional relations between agents involved in such an environment, it was possible to bring much needed transparency to the research efforts aimed at historical reconstruction. This effect occurred, because seeking and naming affordances involved in a given investigated phenomenon by necessity required clear identification of factors which were crucial for its functioning, thus bridging the gap between source data and historians' interpretations. This way, even if unintended and unarticulated, the application of the affordances theory fostered the development of the desirable "material literacies" (Smith \& Hannan, 2017, p. 44) in researchers and precisely separated the physical, time-stable factors from the cultural, interpretation-laden ones. Secondly, the said literacies emerged from different modes of engaging the investigated materiality - desk research, namely mathematical (geometric) modelling and analysis of textual sources, and detailed hands-on archaeological examination were by and large sufficient in the case of the Antikythera Mechanism and the 'Teutonic estoc', but practical kinaesthetic experimentation involving bodies of skilled practitioners and replicas of historical artefacts proved crucial for the study of schiessen.

Moreover, in the last case study the practical experimentation with materiality, congruently with the premises of Gibson's theory, revealed deeper layers of epistemic content, or "ecological knowledge" (Heft, 2001, p. 330), preserved in the dynamic interplay between artefacts and bodies - knowledge which would remain inaccessible, or simply unacknowledged, during static desk research. This suggests that praxiography does not only need to draw from the insights provided by cultural and historical research, but is also well-positioned to contribute significantly to the said studies by incorporating more practice-based, performative and phenomenological modes of inquiry which could be termed "embodied research" (Spatz, 2015, p. 2). As shown by the last example of schiessen, an itemised catalogue of affordances involved in this bodily technique obtained through experimentation demonstrated that its latemedieval author, even if he lacked the language to phrase it, was well-aware of the geometrical, anatomical, and perhaps even neuro-physiological factors at play during combat, which places his knowledge at odds with common generalisations lamenting the deplorable state of 
physical culture in the Middle Ages (Lipoński, 2012). This way, adopting an affordance-based perspective proved useful for revealing implicit knowledge preserved not in textual or visual traces of material culture, but in embodiment and materiality itself.

On a different note, as signalled in the introduction, the way in which the affordances theory was applied in the investigated cases highlighted certain facets of the concept of affordances itself. Gibson's own account of affordances was far from definitive which shifted the burden of their operationalising onto his continuators. As a result, different conceptualisations have been offered so far to expand the concept's original narrow and individualistic definition into a broader affordances landscape (Bruineberg \& Rietveld, 2014) including societal and cultural factors (Heft, 2001; Hodges, 2009). Similarly, the static character of the early takes on affordances was met with more dynamic renderings emphasising the relational and transient aspects, such as "sequential affordances" arising only when some other affordances have already been engaged (Gaver, 1991), or "interactive affordances" emerging from a coregulative activity of multiple agents (Kimmel \& Rogler, 2018). Due to these conceptual explorations, it became increasingly apparent that Gibson's fundamental claim about the direct nature of the perception of affordances is difficult to maintain in the light of empirical findings. Seen from this perspective, the case studies discussed in this paper demonstrate that when material things are detached from the culturally-defined practices they were embedded in, the affordances related to them become far from evident. This may provide further evidence for the social factors mediating the perception of affordances - the concrete material form of the Antikythera Mechanism was a blend of what can be termed 'physical' and 'cultural affordances', whereas the 'Teutonic estoc' was a tool embodying specific technological and martial know-how inaccessible to modern researchers due to cultural constraints, a sort of 'hidden affordance'. In both examples, the specific material objects contained certain epistemic content which became perceivable or even evident only when researchers set the objects in motion, at least imaginatively, in a way meant by their creators - and this required mediation from wider cultural contexts.

Finally, the above observation could be summarised with the common wisdom that "form follows function". But this would require some clarification. First of all, it has to be emphasised that artefacts appear to be relational "bundles of activities" hosting different affordances for different agents and situational contexts (Schatzki, 2002, p. 71) - for instance, children are known to perceive affordances differently when accompanied by an adult (Heft, 2001, pp. 133-134). Moreover, material things call for certain actions, and thus evoke related cognitive states, some of which are suppressed during socialisation, through the so-called "object affordances" (McBride, Sumner, \& Husain, 2012:14), i.e. they provoke automatic pre-activation of motor units related to motions associated with them. However, multiple 'object affordances' are often available in a given agent+tool context and presumably have to compete for the agent's attention in what Thomas Metzinger calls "mental affordance competition" (Metzinger, 2017, p. 13). Over prolonged and repetitive engagements with a given practice, agents transform it by developing skills, but also let their own embodiment and cognition be shaped by it. Through this process, which Spatz calls "sedimented agency", agents' bodies - their only windows to the perceptible material environment - become attuned to certain affordances while being blinded to others (Spatz, 2015, pp. 50-56). Hence, if affordances are to be approached in a way that truly appreciates their dynamics and reciprocity, then every material 
thing has to be defined not only in terms of what it affords, but also the capacity of the embodied agent acting upon it - or, in Michael T. Turvey's terms, the agent's somatic “effectivities", such as strength, height, reflexes, prior training etc. (Turvey, 1992). In a way, the above-mentioned truism could then be reversed into "function follows form", since it is through a circular feedback loop between agents, their effectivities, and the affordances supplied by cultural and material contexts that artefacts are often created so as to mean something specific to somebody concrete. This, in turn, shows that material culture studies sensu lato call not only for practice-based research, but for a one that would be prolonged, repetitive (Smith \& Hannan, 2017), and embodied (Spatz, 2015) in order to give the epistemic content of materiality a chance to pierce through the thick layers of 'sedimented agency' accumulated in researcher's bodies (and minds). To borrow an example from archaeological research one last time, it could be said that material culture scholars have perhaps too long used artefacts to infer the skills and knowledge of their makers, while mostly ignoring those of their users.

\section{Acknowledgment}

I would like to express my deep gratitude to my brother, Szymon Talaga, who drew my attention to ecological psychology and was my first guide in this theoretical framework, as well as to Professor Jerzy Kruppé and Mrs Martyna Milewska, fantastic archaeologists whose broad-mindedness and scholarly sanity keep inspiring me. I am also indepted to my anonymous reviewers whose insightful remarks contributed significantly and positively to the final form of this paper. Finally, I have to mention my old friend and fellow fencer, Piotr Paprzycki, who gladly offered his skills and time during our experimental exploration of the medieval sword-fighting technique discussed above.

\section{References}

Arlander, A., Barton, B., Dreyer-Lude, M., \& Spatz, B. (eds.). (2017). Performance as Research: Knowledge, methods, impact. London: Routledge.

Bender, B. (2006). Place and landscape. In C. Tilley, W. Keane, S. Kuechler, M. Rowlands, P. Spyer (eds.), Handbook of material culture (pp. 303-314). London: Sage.

Brożek, B. (2018). Granice interpretacji. Kraków: Copernicus Center Press.

Bruineberg, J., \& Rietveld, E. (2014). Self-organization, free energy minimization, and optimal grip on a field of affordances. Frontiers in Human Neuroscience, 8, 599. DOI: https://doi.org/10.3389/fnhum.2014.00599

Brylska, A. (2018). Promieniująca czasoprzestrzeń - o statusie czasu i przestrzeni czarnobylskiej zony. Amor Fati, 9(1), 91-111.

Bueger, C. (2014). Pathways to practice praxiography and international politics. European Political Science Review, 6(3), 383-406.

Burkart, E. (2016a). The Autograph of an Erudite Martial Artist: A Close Reading of Nuremberg, Germanisches Nationalmuseum, Hs. 3227a. In Jaquet, D., Verelst, K., \& Dawson, T. (eds.), Late Medieval and Early Modern Fight Books: Transmission and Tradition of Martial Arts in Europe (14th-17th Centuries) (pp. 449-480). Leiden: Brill. 
Burkart, E. (2016b). Limits of Understanding in the Study of Lost Martial Arts. Acta Periodica Duellatorum, 4(2), 5-30.

Chakrabarty, M. (2018). How stone tools shaped us: Post-phenomenology and material engagement theory. Philosophy \& Technology, 32(2), 243-264. DOI: https://doi.org/10.1007/s13347-0180310-x

Costall, A. (1999). An iconoclast's triptych: Edward Reed's ecological philosophy. Theory \& Psychology, 9, 411-416.

Dwiartama, A., \& Rosin, C. (2014). Exploring agency beyond humans: the compatibility of ActorNetwork Theory (ANT) and resilience thinking. Ecology and Society, 19(3). Retrieved from http://www.jstor.org/stable/26269633

Fischer, E. F. (1999). Cultural logic and Maya identity: Rethinking constructivism and essentialism. Current Anthropology, 40(4), 473-500.

Freeth, T., Bitsakis, Y., Moussas, X., Seiradakis, J. H., Tselikas, A., Mangou, H., Zafeiropoulou, M., Hadland, R., Bate, D., Ramsey, A., Allen, M., Crawley, A., Hockley, P., Malzbender, T., Gelb, D., Ambrisco, D., Edmunds, M. G. (2006). Decoding the ancient Greek astronomical calculator known as the Antikythera Mechanism. Nature, 444:7119, 587-591.

Freeth, T. (2012, June). Building the Cosmos in the Antikythera Mechanism. Conference: From Antikythera to the Square Kilometre Array: Lessons from the Ancients. Kerastari, Greece. DOI: 018. 10.22323/1.170.0018.

Gaver, W. (1991). Technology affordances. In S. P. Robertson, G. M. Olson, \& J. S. Olson (eds.), CHI '91 Proceedings of the SIGCHI Conference on Human Factors in Computing Systems (pp. 79-84). New York: ACM.

Gell, A. (1998). Art and agency: an anthropological theory. Oxford: Oxford University Press.

Heft, H. (2001). Ecological psychology in context: James Gibson, Roger Barker, and the legacy of William James's radical empiricism. London: Psychology Press.

Hicks, D., Beaudry, M. C. (2010). Introduction: Material Culture Studies: a Reactionary View. In D. Hicks, M. C. Beaudry (eds.), The Oxford Handbook of Material Culture Studies (pp. 1-21). Oxford.

Hornborg, A. (2017). Artifacts have consequences, not agency: Toward a critical theory of global environmental history. European Journal of Social Theory, 20(1), 95-110. DOI: https://doi.org/10.1177/1368431016640536

Hodges, B. H. (2009). Ecological pragmatics: Values, dialogical arrays, complexity, and caring. Pragmatics \& Cognition, 17(3), 628-652. DOI: https://doi.org/10.1075/pc.17.3.08hod

Ingold, T. (2011). Being alive: Essays on movement, knowledge and description. London: Routledge.

Ingold, T. (2009). The textility of making. Cambridge Journal of Economics, 34(1), 91-102. DOI: https://doi.org/10.1093/cje/bep042

Jaquet, D., Verelst, K., \& Dawson, T. (eds.) (2016). Late Medieval and Early Modern Fight Books: Transmission and Tradition of Martial Arts in Europe (14th-17th Centuries). Leiden: Brill. 
Kimmel, M., \& Rogler, C. R. (2018). Affordances in interaction-the case of Aikido. Ecological Psychology, 30(3), 195-223. DOI: https://doi.org/10.1080/10407413.2017.1409589

Kull, K. (1998). Semiotic ecology: Different natures in the semiosphere. Sign Systems Studies, 26, 344-371.

Latour, B. (1987). Science in Action. How to Follow Scientists and Engineers Through Society. Cambridge: Harvard University Press.

Latour, B. (2017). Anthropology at the time of the Anthropocene: a personal view of what is to be studied. In Brightman, M., Lewis, J. (eds.), The anthropology of sustainability (pp. 35-49). New York: Palgrave Macmillan. DOI: https://doi.org/10.1057/978-1-137-56636-2_2

Lettow, S. (2017). Turning the turn: New materialism, historical materialism and critical theory. Thesis Eleven, 140(1), 106-121, DOI: https://doi.org/10.1177/0725513616683853

Lipoński, W. (2012). Historia sportu na tle rozwoju kultury fizycznej (History of sport against the background of physical culture development). Warszawa: Polskie Wydawnictwo Naukowe.

Martin, E. (2008). A dictionary of biology (6th ed.). Oxford: Oxford University Press.

Mauss, M. (1973). Techniques of the Body. Economy and society, 2(1), 70-88.

McBride, J., Sumner, P., \& Husain, M. (2012). Conflict in object affordance revealed by grip force. The Quarterly Journal of Experimental Psychology, 65(1), 13-24, DOI: https://doi.org/10.1080/17470218.2011.588336

Metzinger, T. (2017). The Problem of Mental Action: Predictive Control without Sensory Sheets. In T. Metzinger \& W. Wiese (eds.), Philosophy and Predictive Processing (pp. 1-26), Frankfurt am Main: MIND Group. DOI: https://doi.org/10.15502/9783958573208

Olsen, B. (2003). Material Culture after Text: Re-Membering Things. Norwegian Archaeological Review, 36(2), 87-104.

Sanderson, P. M. (2003). CHAPTER 9 - Cognitive Work Analysis, In J. M. Carroll (ed.), Interactive Technologies, HCI Models, Theories, and Frameworks (pp. 225-264). New York: Morgan Kaufman.

Schatzki, T. R. (2002). The site of the social: A philosophical account of the constitution of social life and change. University Park: Penn State Press.

Schiffer, M. B. (1999). The Material Life of Human Beings. Artifacts, Behavior, and Communication. London/New York: Routledge.

Segre, S. (2016). Contemporary sociological thinkers and theories. London: Routledge.

Shanks, M. (2005). Experiencing the past: on the character of archaeology. London: Routledge.

Smith K. \& Hannan L. (2017). Return and Repetition: Methods for Material Culture Studies, Journal of Interdisciplinary History, XLVIII(1), 43-59.

Spatz, B. (2015). What a body can do. London: Routledge.

Radtchenko, D. (2006). Simulating the past: Reenactment and the quest for truth in Russia. Rethinking History, 10(1), 127-148. DOI: https://doi.org/10.1080/13642520500474931 
Talaga, M. (2013). A Kampfschwert from the 15th century - a reinterpretation of the so-called 'Teutonic estoc' from the Princes Czartoryski Collection in Cracow, Poland. Acta Periodica Duellatorum, 1(1), 7-27. DOI: https://doi.org/10.1515/apd-2015-0007

Talaga, M. (2018, 6 Jan). Project Hausbuch \#1: Schiessen - essentials of the longsword according to GNM 3227a [blog entry]. Retrieved from: https://www.patreon.com/posts/16167086

Talaga, M. (2019). Narodziny żargonu. Rekonstrukcja znaczenia czasownika schiessen w późnośredniowiecznym niemieckim technolekcie szermierczym. In A. Dombrowski, W. Żarski (eds.), Pojęcie-Kategoria - Stowo w Teorii i Praktyce (pp. 181-202). Wrocław: Wydawnictwo Uniwersytetu Wrocławskiego.

Tonneau, F. (2013). Neorealism: Unifying cognition and environment. Review of General Psychology, 17(2), 237-242. DOI: https://doi.org/10.1037/a0032939

Turvey, M. T. (1992). Affordances and prospective control: An outline of the ontology. Ecological Psychology, 4(3), 173-187. DOI: https://doi.org/10.1207/s15326969eco0403_3

Wilson, S. M., \& Peterson, P. L. (2006). Theories of learning and teaching: What do they mean for educators? Washington, D.C.: National Education Association.

Maciej Talaga received his MA in archaeology in 2012 and joined the 'Nature-Culture' PhD programme at the University of Warsaw in 2018. For the last decade his research interests have revolved around pre-modern European martial traditions, with particular focus on latemedieval Central Europe and the so-called 'German school of fighting' (Kunst des Fechtens). Having initially approached the topic from purely archaeological perspective, he gradually adopted a performative approach combining text- and artefact-based studies with practical experimentation.

The editorial and publishing process of this publication has been financed by the Ministry of Science and Higher Education from the funds for the dissemination of research (DUN) within the framework of publishing activity, contract no. 711/P-DUN/2019, period of implementation: the years 2019-2020. 